\title{
The First Observation of Metallic Behaviour in $\mathrm{Nd}_{3.5} \mathrm{Sm}_{0.5} \mathrm{Ni}_{3} \mathrm{O}_{8}$
}

\author{
Akitoshi Nakata, Syunsuke Yano, Hiroki Yamamoto, Syunsuke Sakura, \\ Yoshihide Kimishima, and Masatomo Uehara
}

Department of Physics, Yokohama National University, Yokohama, Kanagawa 240-8501, Japan

Correspondence should be addressed to Masatomo Uehara; uehara@ynu.ac.jp

Received 29 September 2015; Accepted 4 January 2016

Academic Editor: Rosa Lukaszew

Copyright (c) 2016 Akitoshi Nakata et al. This is an open access article distributed under the Creative Commons Attribution License, which permits unrestricted use, distribution, and reproduction in any medium, provided the original work is properly cited.

In $\mathrm{Nd}_{3.5} \mathrm{Sm}_{0.5} \mathrm{Ni}_{3} \mathrm{O}_{8}$ which has basically the same crystal structure and the similar electrical configuration $\left(\mathrm{Ni}^{+} 3 d^{9} / \mathrm{Ni}^{2+} 3 d^{8} \mathrm{mix}\right.$ valence state) with high- $T_{c}$ cuprate, it has been found that this material shows metallic behaviour down to about $20 \mathrm{~K}$ by intercalation and subsequent deintercalation with sulfur. This is the first observation of the metallic state in this system. It is unclear why sulfurintercalation and deintercalation induce the metallic state. We speculate that sulfur works as an effective getter for removing the interstitial apical oxygen which impedes the metallic conduction. However, the weak localization of carriers in the $\mathrm{NiO}_{2}$ planes still remains below $20 \mathrm{~K}$ and the localization may be one of the obstacles to occurrence of possible superconductivity.

\section{Introduction}

(La, Nd, Sm $)_{n+1} \mathrm{Ni}_{n} \mathrm{O}_{2 n+2}(n=2,3)$ contains 2-dimensional $\mathrm{NiO}_{2}$ planes in the unit cell. Label " $n$ " corresponds to the number of $\mathrm{NiO}_{2}$ planes in the unit cell. The crystal structure is basically the same with high- $T_{c}$ cuprate with two and three $\mathrm{CuO}_{2}$ planes in the unit cell such as $\mathrm{YBa}_{2} \mathrm{Cu}_{3} \mathrm{O}_{y}$ and $\mathrm{Bi}_{2} \mathrm{Sr}_{2} \mathrm{Ca}_{2} \mathrm{Cu}_{3} \mathrm{O}_{y}$. Moreover, the formula valence of $\mathrm{Ni}$ is $+1.33(n=3)$ and $+1.5(n=2)$ consisting of $\mathrm{Ni}^{+} 3 d^{9}$ and $\mathrm{Ni}^{2+} 3 d^{8}$ states. In spite of these structural and electrical similarities with cuprate, $(\mathrm{La}, \mathrm{Nd}, \mathrm{Sm})_{n+1} \mathrm{Ni}_{n} \mathrm{O}_{2 n+2}$ shows neither metallic nature nor superconductivity [1-7]. However, the similarities with cuprate make us expect the occurrence of high- $T_{c}$ superconductivity by tuning the electronic state appropriately such as carrier-doping and applying pressure.

The theoretical studies for $\mathrm{La}_{4} \mathrm{Ni}_{3} \mathrm{O}_{8}(n=3)$ and $\mathrm{La}_{3} \mathrm{Ni}_{2} \mathrm{O}_{6}(n=2)$ have been performed [7-10]. In $\mathrm{La}_{4} \mathrm{Ni}_{3} \mathrm{O}_{8}$ it has been predicted that $[7,8]$ at $T>105 \mathrm{~K}$ the material is in a low-spin state and is metallic but, at $T<105 \mathrm{~K}$, becomes in high-spin state and is insulating because of quantum confinement within the $\mathrm{NiO}_{2}$-trilayers [8]. By applying a pressure of $5 \mathrm{GPa}$, it has been predicted that the high-spin state disappears and the system takes the lowspin state, resulting in a metal-insulator transition [7]. The insulating behaviour of $\mathrm{La}_{3} \mathrm{Ni}_{2} \mathrm{O}_{6}$ has also been predicted to be due to quantum confinement within the $\mathrm{NiO}_{2}$-double layers [10]. The electrical resistivity $(\rho)$ of $\mathrm{La}_{4} \mathrm{Ni}_{3} \mathrm{O}_{8}$ under pressure indicates a suppression of the high-spin state and reduction of $\rho$ [11]. However, neither the metallic state nor superconductivity has been observed [11]. Experimentally, this material is an insulator even at $T>105 \mathrm{~K}$. Regarding this discrepancy between experiment and theory, Pardo and Pickett interpret that part of the $\mathrm{Ni}$ is not in a low-spin state even at high temperature [7]. If all the $\mathrm{Ni}$ atoms take lowspin state, an insulator-metal transition will occur and the emergence of superconductivity can be expected.

In our previous chemical pressure experiments for ( $\mathrm{La}$, $\mathrm{Nd}, \mathrm{Sm})_{4} \mathrm{Ni}_{3} \mathrm{O}_{8}$, the clear correlation between the $a$-axis length and $\rho$ was observed [12]. $\mathrm{Nd}_{3.5} \mathrm{Sm}_{0.5} \mathrm{Ni}_{3} \mathrm{O}_{8}$ has the shortest $a$-axis length and the smallest $\rho$ at $300 \mathrm{~K}$ in (La, $\mathrm{Nd}, \mathrm{Sm})_{4} \mathrm{Ni}_{3} \mathrm{O}_{8}$ solid solution. The electrical resistivity measurements under pressure of $0-3 \mathrm{GPa}$ for $\mathrm{Nd}_{3.5} \mathrm{Sm}_{0.5} \mathrm{Ni}_{3} \mathrm{O}_{8}$ suggest a suppression of the high-spin state and reduction of $\rho$ down to $10^{-1}(\mathrm{Ohm} \cdot \mathrm{cm})$ at room temperature [13]. However, neither the metallic state nor superconductivity was obtained being the same result as for $\mathrm{La}_{4} \mathrm{Ni}_{3} \mathrm{O}_{8}$. In order to obtain metallic state and superconductivity, the other strategy in addition to the application of pressure is necessary.

In this paper we report that $\mathrm{Nd}_{3.5} \mathrm{Sm}_{0.5} \mathrm{Ni}_{3} \mathrm{O}_{8}$ shows metallic behaviour down to about $20 \mathrm{~K}$ by intercalation and subsequent deintercalation with sulfur. This is the first observation of the metallic state in this system. 


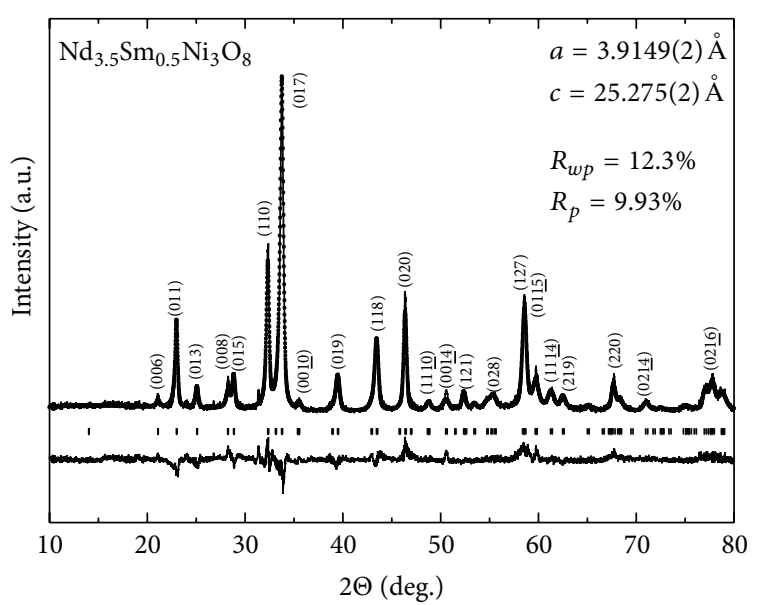

FIgURE 1: XRD data for $\mathrm{Nd}_{3.5} \mathrm{Sm}_{0.5} \mathrm{Ni}_{3} \mathrm{O}_{8}$. Tick marks and bottom solid line are Bragg positions and difference between calculated and observed data, respectively.

\section{Experimental}

At first $\mathrm{Nd}_{3.5} \mathrm{Sm}_{0.5} \mathrm{Ni}_{3} \mathrm{O}_{10}$ was synthesized by solid state reaction and the detail was reported in our previous paper [12]. Next, resultant $\mathrm{Nd}_{3.5} \mathrm{Sm}_{0.5} \mathrm{Ni}_{3} \mathrm{O}_{10}$ was annealed for $5 \mathrm{~h}$ at $400^{\circ} \mathrm{C}$ under flowing hydrogen to reduce $\mathrm{Nd}_{3.5} \mathrm{Sm}_{0.5} \mathrm{Ni}_{3} \mathrm{O}_{10}$ to $\mathrm{Nd}_{3.5} \mathrm{Sm}_{0.5} \mathrm{Ni}_{3} \mathrm{O}_{8}$.

Sulfur-intercalation was performed in evacuated Pyrex ${ }^{\oplus}$ glass tube together with a 10 weight $\%$ sulfur pellet at $400^{\circ} \mathrm{C}$ for $5 \mathrm{~h}$. Sulfur-deintercalation was performed in tube furnace at $350^{\circ} \mathrm{C}$ for $3 \mathrm{~h}$ under flowing hydrogen gas.

The samples were checked by X-ray diffraction (XRD) using $\mathrm{Cu} \mathrm{K} \alpha$ radiation. Rietveld analysis was carried out by using RIETAN-2000 program [14]. The electrical resistivity measurements were performed by conventional four-probe method. Magnetic data were collected by Quantum Design MPMS magnetometer.

\section{Results and Discussion}

Figure 1 shows the XRD pattern for $\mathrm{Nd}_{3.5} \mathrm{Sm}_{0.5} \mathrm{Ni}_{3} \mathrm{O}_{8}$ before sulfur-intercalation. XRD pattern indicates that the sample is almost single-phase. Rietveld analysis was performed by using the crystal model reported previously [3]. Bottom solid line shows the difference between observed and calculated data. From this analysis, the lattice parameters $a=3.9149$ (2) $\AA$ and $c=25.275(2) \AA$ were obtained.

As previously reported, $\rho$ for $\mathrm{Nd}_{3.5} \mathrm{Sm}_{0.5} \mathrm{Ni}_{3} \mathrm{O}_{8}$ without sulfur-intercalation shows insulating behaviour, which remains insulating under pressure up to $3 \mathrm{GPa}$ [13]. In order to obtain metallic state, sulfur-intercalation was tried. Assuming that formal valence of sulfur is -2 , the intercalation corresponds to hole-doping. Figure 3 shows the XRD pattern for $\mathrm{Nd}_{3.5} \mathrm{Sm}_{0.5} \mathrm{Ni}_{3} \mathrm{O}_{8}$ after sulfur-intercalation. $\mathrm{S} / \mathrm{N}$ ratio of $\mathrm{XRD}$ pattern is not so good because of a small amount of the sample. XRD pattern can be indexed by tetragonal symmetry with $a=3.8548(8) \AA$ and $c=26.883(9) \AA$. Comparing to $\mathrm{Nd}_{3.5} \mathrm{Sm}_{0.5} \mathrm{Ni}_{3} \mathrm{O}_{8}$ before sulfur-intercalation, $a$-axis shrinks at $1.5 \%$ and $c$-axis expands at $6.4 \%$. There exists $\mathrm{La}_{4} \mathrm{Ni}_{3} \mathrm{O}_{9}$ and this material can be regarded as the compound that an oxygen atom is intercalated in-between sites of $\mathrm{NiO}_{2}$ layer of $\mathrm{La}_{4} \mathrm{Ni}_{3} \mathrm{O}_{8}$ having the identical structure to $\mathrm{Nd}_{3.5} \mathrm{Sm}_{0.5} \mathrm{Ni}_{3} \mathrm{O}_{8}$ $[15,16]$. By this oxygen-intercalation for $\mathrm{La}_{4} \mathrm{Ni}_{3} \mathrm{O}_{8}, a$-axis is shrunk at $2 \%$ and $c$-axis is expanded at $5 \%[15,16]$. The variation of lattice constants of oxygen-intercalation has the very similar tendency with the case of sulfur-intercalation for $\mathrm{Nd}_{3.5} \mathrm{Sm}_{0.5} \mathrm{Ni}_{3} \mathrm{O}_{8}$. From this fact, it is natural that sulfur ions are expected to be intercalated in-between sites of $\mathrm{NiO}_{2}$ layers. Even though $\mathrm{S} / \mathrm{N}$ ratio of XRD data is not good due to small amount of sample volume, tentative Rietveld analysis was applied to this sample based on the same crystal model $(I 4 / \mathrm{mmm})$ with $\mathrm{Nd}_{3.5} \mathrm{Sm}_{0.5} \mathrm{Ni}_{3} \mathrm{O}_{8}$ plus sulfur ions sitting in-between sites of $\mathrm{NiO}_{2}$ layers $(4 e$ site $(0,0,0.06)$ ). Variable parameters were set to be lattice constants and sulfur occupancy of $4 e$ site. From this analysis, it has been found that XRD pattern can reasonably be explained by this model and sulfur content was determined to be $\mathrm{Nd}_{3.5} \mathrm{Sm}_{0.5} \mathrm{Ni}_{3} \mathrm{O}_{8} \mathrm{~S}_{0.7 \pm 0.2}$.

By sulfur-intercalation, $\rho$ was decreased from $10^{0}(\mathrm{Ohm} \cdot \mathrm{cm})$ down to $10^{-1}(\mathrm{Ohm} \cdot \mathrm{cm})$ as shown in Figure 4. However, temperature dependence of $\rho$ remains semiconductive. Although the amount of intercalated sulfur is relatively large $(0.7 \pm 0.2$ at a molar ratio), the reduction of $\rho$ is at most of one order. The superconductivity of this system is thought to appear on the basis of the similarity with the 2-dimensional high$T_{c}$ cuprate. Sulfur-intercalation spoils the structural similarity with high- $T_{c}$ cuprate, even though the system approaches to metallic phase. Therefore, the strategy of sulfur-intercalation by obtaining the metallicity does not seem to be promising.

Next, we performed the sulfur-deintercalation with the condition mentioned in experimental section. Figure 2 shows XRD pattern for $\mathrm{Nd}_{3.5} \mathrm{Sm}_{0.5} \mathrm{Ni}_{3} \mathrm{O}_{8} \mathrm{~S}_{0.7}$ after sulfur-deintercalation. Bad $\mathrm{S} / \mathrm{N}$ ratio of XRD pattern is attributed to a small amount of the sample. XRD profile seems to return to that of as-synthesized $\mathrm{Nd}_{3.5} \mathrm{Sm}_{0.5} \mathrm{Ni}_{3} \mathrm{O}_{8}$. Therefore, sulfur ions are thought to be successfully deintercalated. Figure 5 shows the temperature dependence of $\rho$ for sulfur-deintercalated $\mathrm{Nd}_{3.5} \mathrm{Sm}_{0.5} \mathrm{Ni}_{3} \mathrm{O}_{8}$. Contrary to expectation, $\rho$ shows metallic behaviour down to $20 \mathrm{~K}$. It is natural to expect that $\rho$ exhibits semiconducting behaviour because the original crystal structure possessing semiconducting nature is recovered. Below $20 \mathrm{~K}$, the electrical conduction is localized and the superconductivity was not observed down to $2 \mathrm{~K}$. The weak semiconducting behaviour below $20 \mathrm{~K}$ obeys the 2-dimensional variable range hopping $(\mathrm{VRH}) \operatorname{model}\left(\rho \propto \exp \left(C \cdot T^{-1 / 3}\right), C=\right.$ constant), reflecting the 2-dimensional intralayer hopping of carriers in the $\mathrm{NiO}_{2}$ planes. The temperature dependence of $\log \rho$ for sulfur-deintercalated $\mathrm{Nd}_{3.5} \mathrm{Sm}_{0.5} \mathrm{Ni}_{3} \mathrm{O}_{8}$ as a function of $T^{-1 / 3}$ appears to be almost linear below about $20 \mathrm{~K}$ as seen in Figure 6. It should be noted that the fitting result was not so bad in 3-dimensional case too (not shown). This might come from a small variation of $\rho(T)$ in the narrow temperature range used by fitting procedure. Otherwise, it might be inherently difficult to strictly appreciate the dimensionality by using VRH model, because in this material three $\mathrm{NiO}_{2}$ planes are stacked perpendicular to 2-dimensional $\mathrm{NiO}_{2}$ plane and hence interlayer hopping is also possible. 


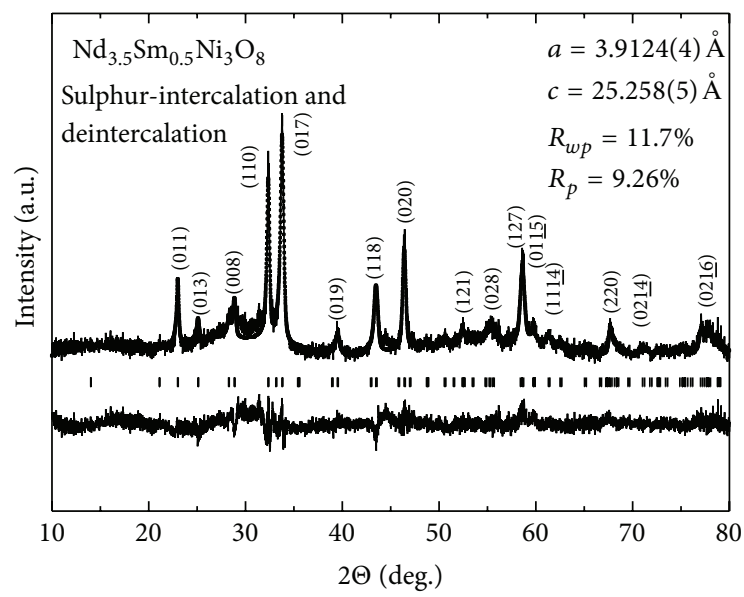

FIgURE 2: XRD data for sulfur-deintercalated $\mathrm{Nd}_{3.5} \mathrm{Sm}_{0.5} \mathrm{Ni}_{3} \mathrm{O}_{8}$. Tick marks and bottom solid line are Bragg positions and difference between calculated and observed data, respectively.

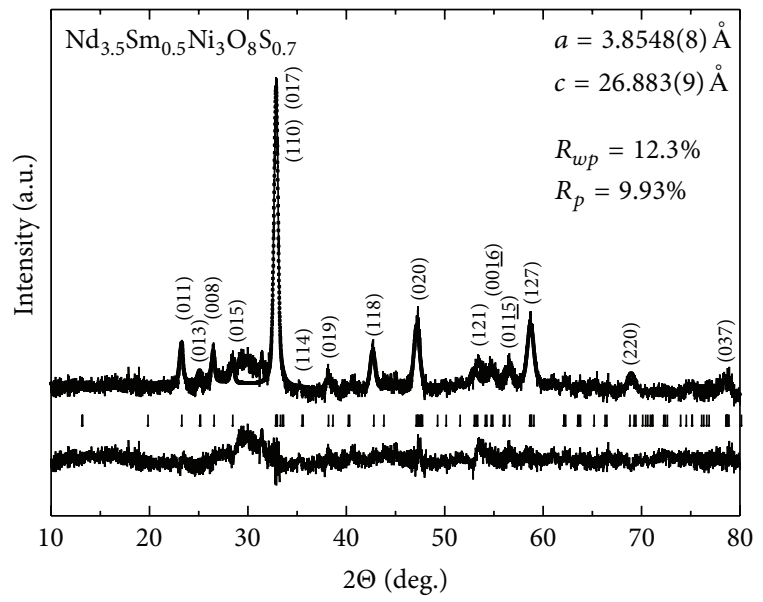

FIguRE 3: XRD data for $\mathrm{Nd}_{3.5} \mathrm{Sm}_{0.5} \mathrm{Ni}_{3} \mathrm{O}_{8} \mathrm{~S}_{0.68}$. Tick marks and bottom solid line are Bragg positions and difference between calculated and observed data, respectively.

The possibility that the metallic behaviour comes from the existence of metallic impurity such as elemental Ni should be considered. Actually very small amount of elemental $\mathrm{Ni}$ is detectable in XRD data of Figure 2. In order to know how much elemental Ni exists in the sample, the magnetization measurement as a function of external field was performed at $5 \mathrm{~K}$ (see Figure 7 ). The extrapolated value to $0 \mathrm{Oe}$ of the linear curve fitted to the magnetization data of $15-35 \mathrm{kOe}$ is $1.3(\mathrm{emu} / \mathrm{g})$. The result means that the sample contains only about 2.2 weight $\%$ ferromagnetic Ni. This corresponds to be far below the percolation threshold. Therefore, the metallic nature is thought to be intrinsic.

In order to know what happens by sulfur-deintercalation, Rietveld analysis was tentatively performed, though the quality of XRD data is not so good due to small amount of sample. The best fitting result was obtained with the crystal model in which $10 \%$ sulfur ions replace the oxygen site $(0,1 / 2,1 / 4)$ in block layer and oxygen ions of $\mathrm{NiO}_{2}$ plane are not replaced

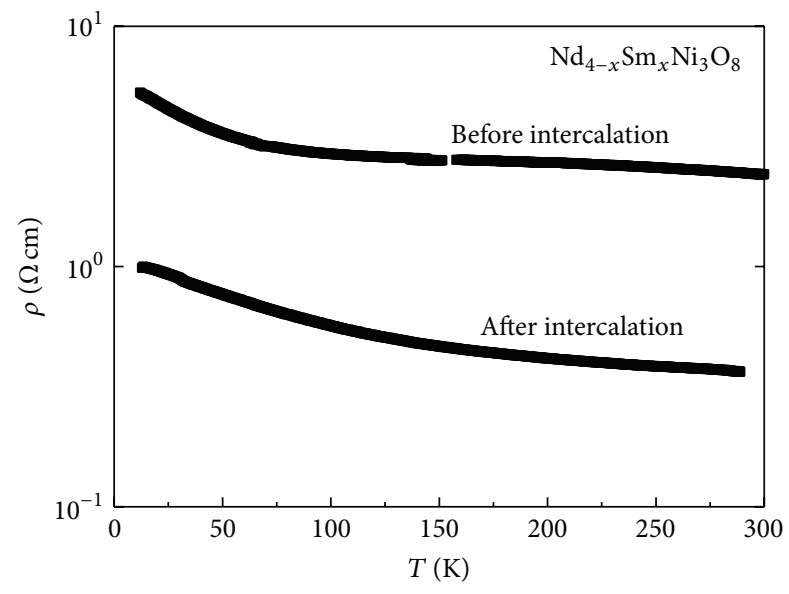

FIGURE 4: Temperature dependence of $\mathrm{Nd}_{3.5} \mathrm{Sm}_{0.5} \mathrm{Ni}_{3} \mathrm{O}_{8}$ and sulfur intercalated $\mathrm{Nd}_{3.5} \mathrm{Sm}_{0.5} \mathrm{Ni}_{3} \mathrm{O}_{8} \mathrm{~S}_{0.68}$.

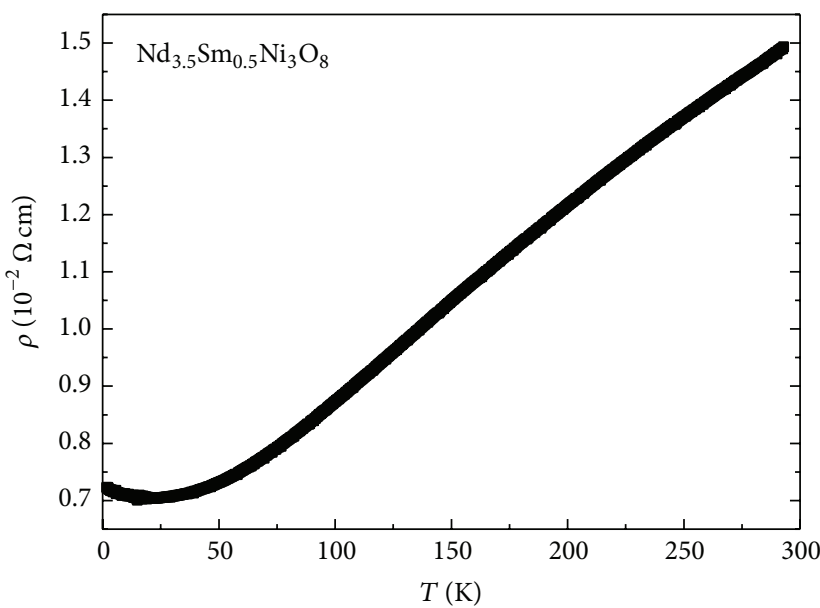

Figure 5: Temperature dependence of $\rho$ for sulfur-deintercalated $\mathrm{Nd}_{3.5} \mathrm{Sm}_{0.5} \mathrm{Ni}_{3} \mathrm{O}_{8}$

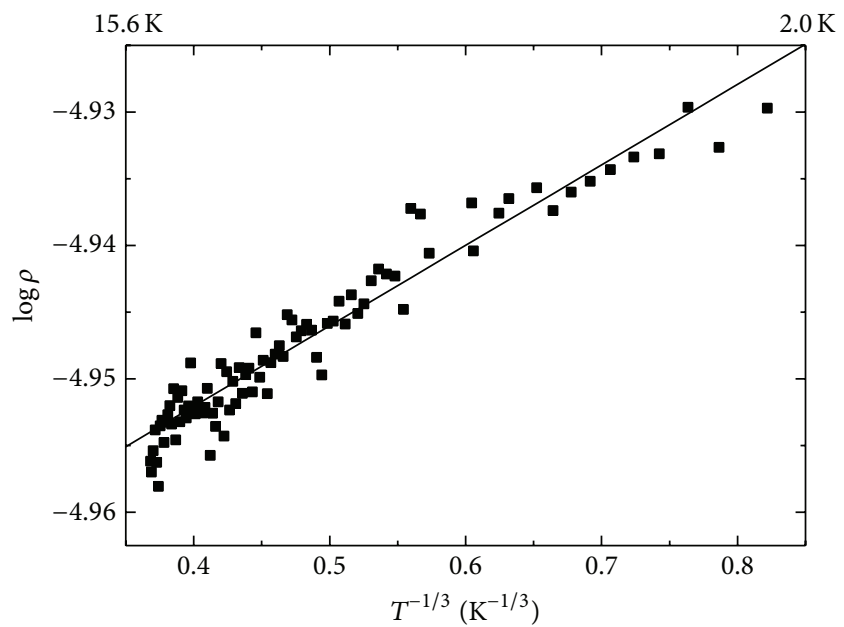

FIGURE 6: $T^{-1 / 3}$ dependence of $\log \rho$ for sulfur-deintercalated $\mathrm{Nd}_{3.5} \mathrm{Sm}_{0.5} \mathrm{Ni}_{3} \mathrm{O}_{8}$. 


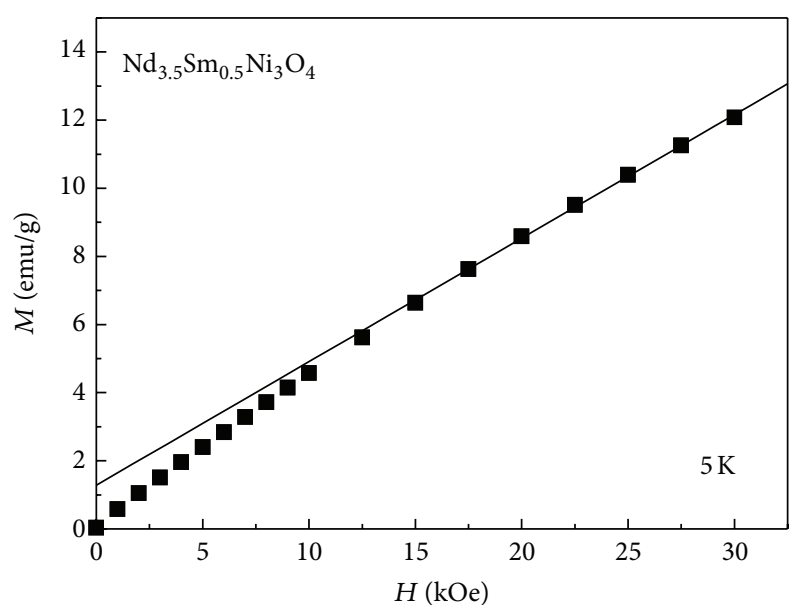

Figure 7: Field dependence of magnetization for sulfur-deintercalated $\mathrm{Nd}_{3.5} \mathrm{Sm}_{0.5} \mathrm{Ni}_{3} \mathrm{O}_{8}$.

by sulfur. If sulfur doping to oxygen site really takes place, ionic state of sulfur is thought to be -2 , considering the ionic size matching between sulfur and oxygen. In this case, band filling of the material does not change. However, the replacement of as large amount as $10 \%$ sulfur to oxygen site seems to be unreasonable because the change of lattice parameters as mentioned below is very small considering the size difference between sulfur and oxygen. Even if the replacement with sulfur takes place, the amount may be much smaller than $10 \%$. The Rietveld fitting result is shown in Figure 2. The lattice parameters $a(c)$-axis are shrunk from 3.9149(2) $\AA(25.275(2) \AA)$ to 3.9124(4) $\AA$ (25.258(5) $\AA)$, comparing the sample without sulfur-intercalation and deintercalation. However, the variations are as small as about $0.1 \%$.

The block layer separating $\mathrm{NiO}_{2}$ planes is of fluorite type, similar to $T^{\prime}$-type high- $T_{c}$ cuprate. It has been known that $T^{\prime}$-type structure tends to incorporate the additional oxygen into the apical oxygen site and this oxygen is a strong obstacle against the superconductivity [17]. We speculate that in $\mathrm{Nd}_{3.5} \mathrm{Sm}_{0.5} \mathrm{Ni}_{3} \mathrm{O}_{8}$ the additional apical oxygen exists and the sulfur ions work as an effective oxygen getter for the additional oxygen. Because hydrogen gas is used during sulfur-deintercalation, the hypothesis might be possible as follows: hydrogen chemically reacts with sulfur in the crystal, producing $\mathrm{H}_{2} \mathrm{~S}$, and $\mathrm{H}_{2} \mathrm{~S}$ is going outside the crystal. At the same time, reducing agent $\mathrm{H}_{2} \mathrm{~S}$ effectively removes the additional apical oxygen with the chemical reaction such as $\mathrm{H}_{2} \mathrm{~S}+\mathrm{O}$ (apical) $\rightarrow \mathrm{H}_{2} \mathrm{O}+\mathrm{S}$.

In structurally related compounds $T^{\prime}$-type high- $T_{c}$ cuprate and $\mathrm{LaNiO}_{2}$, removal of the additional apical oxygen causes the shrinkage of $c$-axis length [18-22]. In $\mathrm{Nd}_{3.5} \mathrm{Sm}_{0.5} \mathrm{Ni}_{3} \mathrm{O}_{8}$ the shrinkage of $c$-axis has been observed (from 25.275(2) to 25.258(5) $\AA$ ) by sulfur-deintercalation. However, the amount of removal of additional oxygen seems to be not enough for inducing the metallicity below $20 \mathrm{~K}$, because the variation of $c$-axis is smaller (about $0.1 \%$ ) than that for inducing the metallicity and superconductivity in $T^{\prime}$-type high- $T_{c}$ cuprate. For example of $T^{\prime}$-type $\mathrm{Sm}_{2} \mathrm{CuO}_{4}$ film, the superconductivity can be induced by appropriate reducing annealing, accompanied by the shrinkage of $c$-axis with $0.25 \%$ [20]. In order to clarify the detailed structural change by sulfurdeintercalation, X-ray diffraction with synchrotron source or neutron diffraction experiments are needed.

\section{In Conclusion}

In $\mathrm{Nd}_{3.5} \mathrm{Sm}_{0.5} \mathrm{Ni}_{3} \mathrm{O}_{8}$ which has basically the same crystal structure and the similar electrical configuration $\left(\mathrm{Ni}^{+}\right.$ $3 d^{9} / \mathrm{Ni}^{2+} 3 d^{8}$ mix valence state) with high- $T_{c}$ cuprate, it has been found that this material shows metallic behaviour down to about $20 \mathrm{~K}$ by intercalation and subsequent deintercalation with sulfur. This is the first observation of the metallic state in this system. It is unclear why sulfur-intercalation and deintercalation induce the metallic state. We speculate that sulfur works as an effective getter for removing the interstitial apical oxygen which impedes the metallic conduction. However, the weak localization of carriers still remains below $20 \mathrm{~K}$ in the $\mathrm{NiO}_{2}$ planes. In order to obtain the metallicity below $20 \mathrm{~K}$ and to clarify whether the superconductivity really appears or not, the appropriate annealing condition for removing only interstitial apical oxygen cleanly has to be found out.

\section{Conflict of Interests}

The authors declare that there is no conflict of interests regarding the publication of this paper.

\section{References}

[1] R. Retoux, J. Rodriguez-Carvajal, and P. Lacorre, "Neutron diffraction and TEM studies of the crystal structure and defects of $\mathrm{Nd}_{4} \mathrm{Ni}_{3} \mathrm{O}_{8}$," Journal of Solid State Chemistry, vol. 140, no. 2, pp. 307-315, 1998.

[2] V. V. Poltavets, K. A. Lokshin, S. Dikmen, M. Croft, T. Egami, and M. Greenblatt, " $\mathrm{La}_{3} \mathrm{Ni}_{2} \mathrm{O}_{6}$ : a new double $\mathrm{T}$ '-type nickelate with infinite $\mathrm{Ni}^{1+/ 2+} \mathrm{O}_{2}$ layers," Journal of the American Chemical Society, vol. 128, no. 28, pp. 9050-9051, 2006.

[3] V. V. Poltavets, K. A. Lokshin, M. Croft, T. K. Mandal, T. Egami, and M. Greenblatt, "Crystal structures of $\mathrm{Ln}_{4} \mathrm{Ni}_{3} \mathrm{O}_{8}(\mathrm{Ln}=\mathrm{La}$, $\mathrm{Nd}$ ) triple layer $\mathrm{T}^{\prime}$-type nickelates," Inorganic Chemistry, vol. 46, no. 25, pp. 10887-10891, 2007.

[4] V. V. Poltavets, K. A. Lokshin, A. H. Nevidomskyy et al., "Bulk magnetic order in a two-dimensional $\mathrm{Ni}^{1+} / \mathrm{Ni}^{2+}\left(\mathrm{d}^{9} / \mathrm{d}^{8}\right)$ nickelate, isoelectronic with superconducting cuprates," Physical Review Letters, vol. 104, no. 20, Article ID 206403, 2010.

[5] N. ApRoberts-Warren, A. P. Dioguardi, V. V. Poltavets, M. Greenblatt, P. Klavins, and N. J. Curro, "Critical spin dynamics in the antiferromagnet $\mathrm{La}_{4} \mathrm{Ni}_{3} \mathrm{O}_{8}$ from ${ }^{139} \mathrm{La}$ nuclear magnetic resonance," Physical Review B, vol. 83, no. 1, Article ID 014402, 2011.

[6] V. V. Poltavets, M. Greenblatt, G. H. Fecher, and C. Felser, "Electronic properties, band structure, and fermi surface instabilities of $\mathrm{Ni}^{1+} / \mathrm{Ni}^{2+}$ nickelate $\mathrm{La}_{3} \mathrm{Ni}_{2} \mathrm{O}_{6}$, isoelectronic with superconducting cuprates," Physical Review Letters, vol. 102, no. 4, Article ID 046405, 2009.

[7] V. Pardo and W. E. Pickett, "Pressure-induced metal-insulator and spin-state transition in low-valence layered nickelates," Physical Review B, vol. 85, no. 4, Article ID 045111, 6 pages, 2012. 
[8] V. Pardo and W. E. Pickett, "Quantum confinement induced molecular correlated insulating state in $\mathrm{La}_{4} \mathrm{Ni}_{3} \mathrm{O}_{8}$," Physical Review Letters, vol. 105, no. 26, Article ID 266402, 2010.

[9] S. Sarkar, I. Dasgupta, M. Greenblatt, and T. Saha-Dasgupta, "Electronic and magnetic structures of bilayer $\mathrm{La}_{3} \mathrm{Ni}_{2} \mathrm{O}_{6}$ and trilayer $\mathrm{La}_{4} \mathrm{Ni}_{3} \mathrm{O}_{8}$ nickelates from first principles," Physical Review B, vol. 84, no. 18, Article ID 180411, 2011.

[10] V. Pardo and W. E. Pickett, "Metal-insulator transition in layered nickelates $\mathrm{La}_{3} \mathrm{Ni}_{2} \mathrm{O}_{7-\delta}(\delta=0.0,0.5,1)$," Physical Review $B$, vol. 83, no. 24, Article ID 245128, 7 pages, 2011.

[11] J.-G. Cheng, J.-S. Zgou, J. B. Goodenough et al., "Pressure effect on the structural transition and suppression of the high-spin state in the triple-layer $T^{\prime}-\mathrm{La}_{4} \mathrm{Ni}_{3} \mathrm{O}_{8}$," Physical Review Letters, vol. 108, no. 23, Article ID 236403, 2012.

[12] Y. Sakurai, N. Chiba, Y. Kimishima, and M. Uehara, "Electronic and magnetic properties of $\mathrm{La}_{4} \mathrm{Ni}_{3-x} \mathrm{Cu}_{x} \mathrm{O}_{8}$ and $\mathrm{Nd}_{4-y} \mathrm{Sm}_{y} \mathrm{Ni}_{3} \mathrm{O}_{8}$, Physica C: Superconductivity, vol. 487, pp. 27-30, 2013.

[13] Y. Sakurai, S. Sakura, G. Hu et al., "Pressure effects of $\mathrm{Nd}_{3.5} \mathrm{Sm}_{0.5} \mathrm{Ni}_{3} \mathrm{O}_{8}$ and $\mathrm{La}_{3-x} \mathrm{Nd}_{x} \mathrm{Ni}_{2} \mathrm{O}_{6}$ ", JPS Conference Proceedings, vol. 1, Article ID 012086, pp. 1-4, 2014.

[14] F. Izumi and T. Ikeda, "A rietveld-analysis programm RIETAN98 and its applications to zeolites," Materials Science Forum, vol. 321-324, pp. 198-205, 2000.

[15] C. K. Blakely, S. R. Bruno, and V. V. Poltavets, "Low-temperature solvothermal approach to the synthesis of $\mathrm{La}_{4} \mathrm{Ni}_{3} \mathrm{O}_{8}$ by topotactic oxygen deintercalation," Inorganic Chemistry, vol. 50, no. 14, pp. 6696-6700, 2011.

[16] P. Lacorre, "Passage from T-type to $\mathrm{T}^{\prime}$-type arrangement by reducing $R_{4} \mathrm{Ni}_{3} \mathrm{O}_{10}$ to $R_{4} \mathrm{Ni}_{3} \mathrm{O}_{8}(R=\mathrm{La}, \mathrm{Pr}, \mathrm{Nd})$," Journal of Solid State Chemistry, vol. 97, no. 2, pp. 495-500, 1992.

[17] M. Imada, A. Fujimori, and Y. Tokura, "Metal-insulator transitions," Reviews of Modern Physics, vol. 70, no. 4, pp. 1039-1263, 1998.

[18] A. Tsukada, M. Noda, H. Yamamoto, and M. Naito, "Role of impurity oxygen in superconductivity of 'non-doped' $T$ ' -(La, $\mathrm{RE})_{2} \mathrm{CuO}_{4}$," Physica C: Superconductivity, vol. 426-431, part 1, pp. 459-463, 2005.

[19] O. Matsumoto, A. Utsuki, A. Tsukada, H. Yamamoto, T. Manabe, and M. Naito, "Reduction dependence of superconductivity in the end-member T' cuprates," Physica C: Superconductivity and Its Applications, vol. 469, no. 15-20, pp. 940-943, 2009.

[20] O. Matsumoto, A. Utsuki, A. Tsukada, H. Yamamoto, T. Manabe, and M. Naito, "Synthesis and properties of superconducting $T^{\prime}-\mathrm{R}_{2} \mathrm{CuO}_{4}(\mathrm{R}=\mathrm{Pr}, \mathrm{Nd}, \mathrm{Sm}, \mathrm{Eu}, \mathrm{Gd})$," Physical Review $B$, vol. 79, no. 10, Article ID 100508(R), 4 pages, 2009.

[21] A. Ikeda, T. Manabe, and M. Naito, "Improved conductivity of infinite-layer $\mathrm{LaNiO}_{2}$ thin films by metal organic decomposition," Physica C: Superconductivity and its Applications, vol. 495, pp. 134-140, 2013.

[22] A. Ikeda, T. Manabe, and M. Naito, "Comparison of reduction agents in the synthesis of infinite-layer $\mathrm{LaNiO}_{2}$ films," Physica C: Superconductivity and its Applications, vol. 506, pp. 83-86, 2014. 

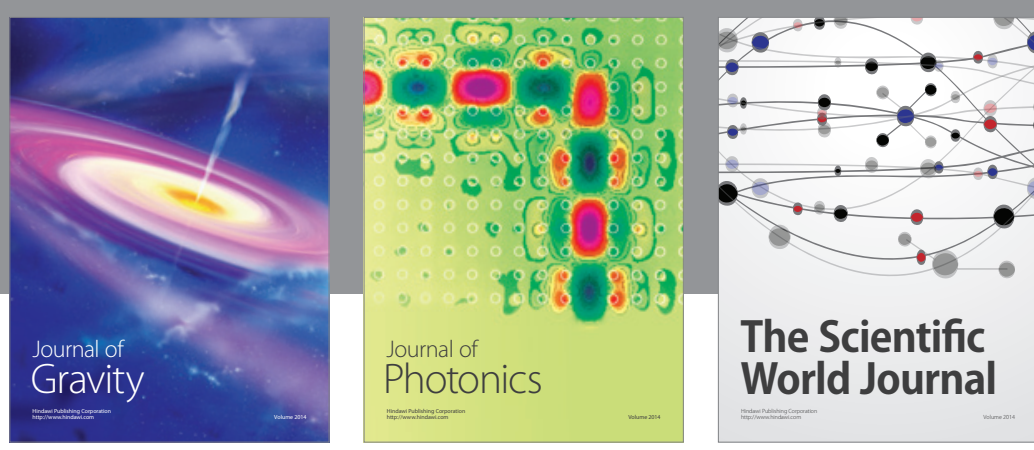

The Scientific World Journal
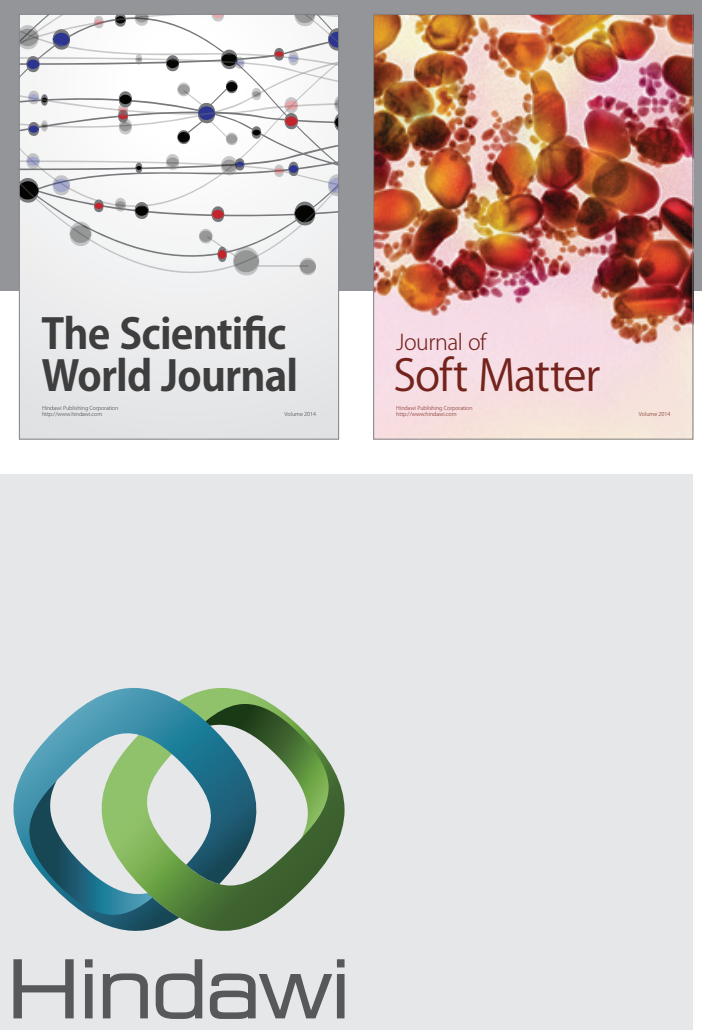

Submit your manuscripts at

http://www.hindawi.com

nternational Journal of

Statistical Mechanics
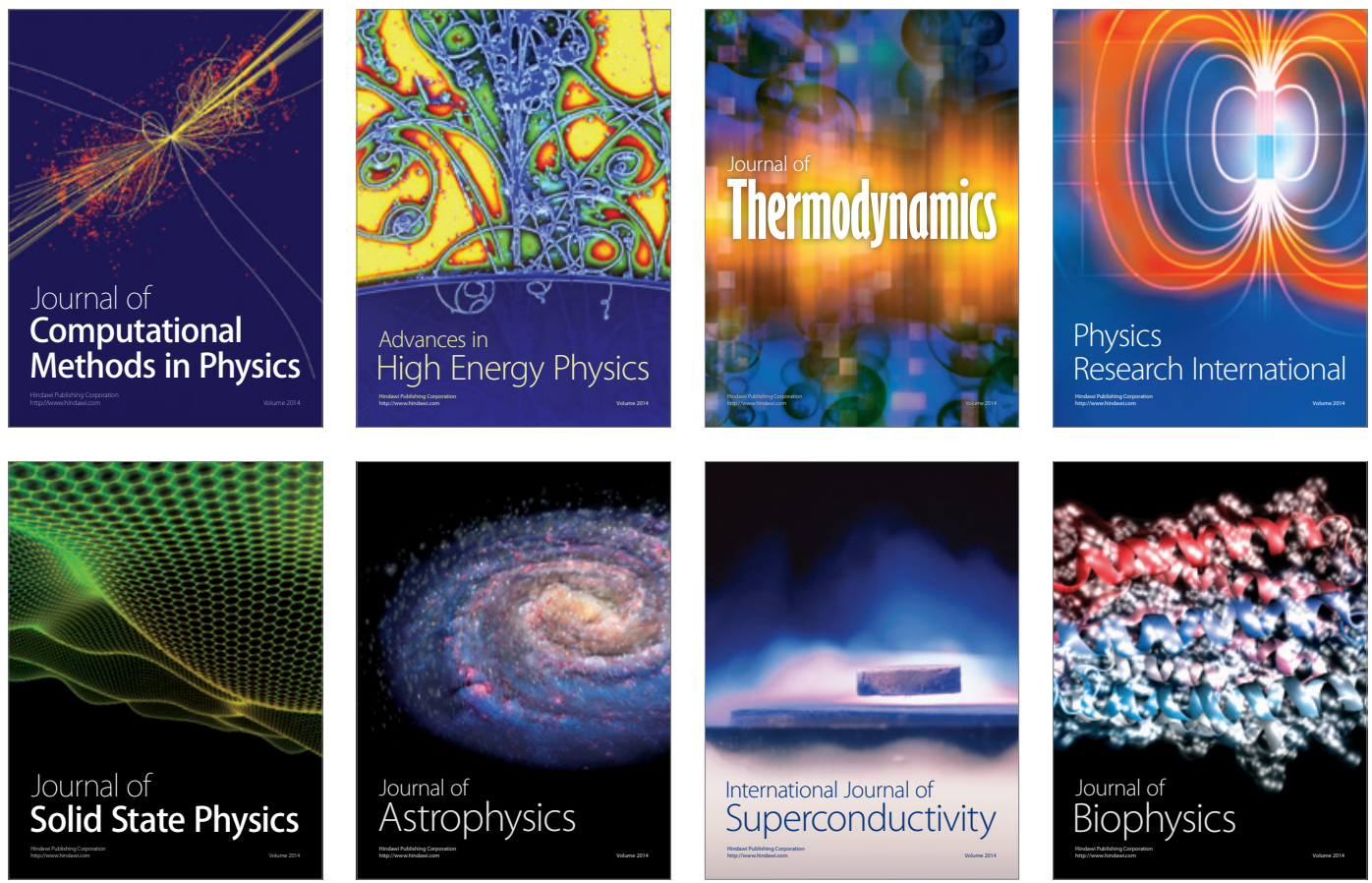
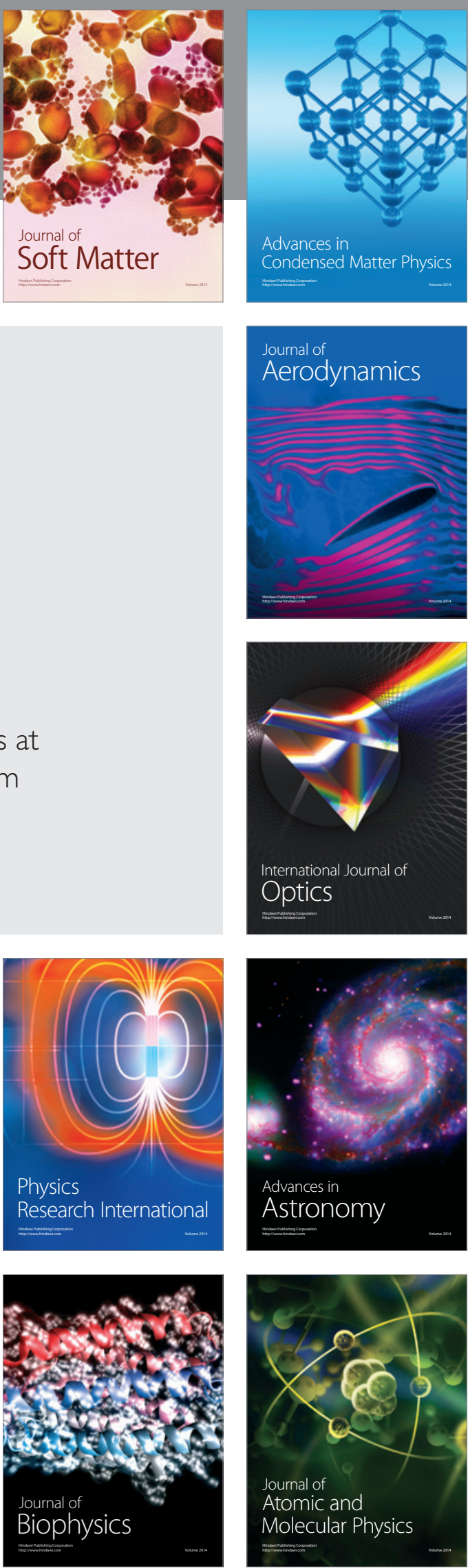